\title{
Desestabilização do trabalho
}

\author{
Work destabilization
}

Marcio Pochmann 1

DOI: 10.1590/0103-11042018S306

RESUMO O presente ensaio analisou aspectos da desestabilização do mundo do trabalho presente nas situações de crise que marcam o desenvolvimento do capitalismo. Os dois principais movimentos estruturais a desestabilizar a sentido do trabalho assentam-se, em geral, no excepcional progresso do avanço tecnológico em meio ao acirramento da competição intercapitalista e no papel do Estado em relação à regulação do crescente excedente de força de trabalho às necessidades do capital. Nessa dimensão analítica, contrastam-se promessas de ascensão ao mundo do trabalho com a realidade da precarização e resistência organizada.

PALAVRAS-CHAVE Trabalho. Política. Sociedades.

ABSTRACT This essay analyzes aspects of the destabilization of the world of labor present in the crisis situations that mark the development of capitalism. The two main structural movements to destabilize the sense of work are generally based on the exceptional progress of technological advancement amid the intensification of intercapitalist competition and on the role of the State regarding the regulation of the growing labor force surplus to the needs of the capital. In this analytical dimension, we contrast the promises of ascension to the world of labor with the reality of precariousness and organized resistance.

KEYWORDS Work. Politics. Societies.

1 Universidade Estadual de Campinas (Unicamp),

Instituto de Economia

e Centro de Estudos

Sindicais e de Economia do

Trabalho - Campinas (SP),

Brasil.

Orcid: https://orcid

org/0000-0002-3940-

1536

pochmann@unicamp.br 


\section{Introdução}

[...] uma calamidade social é basicamente um fenômeno cultural e não um fenômeno econômico que pode ser medido por cifras de rendimentos ou estatísticas populacionais. [...] a Revolução Industrial [foi] um terremoto econômico que em menos de meio século transformou grandes massas de habitantes do campo inglês de gente estabelecida em migrantes ineptos. Todavia, se desmoronamentos destrutivos como esses são excepcionais na história das classes, eles são uma ocorrência comum na esfera dos contatos culturais entre povos de raças diferentes. Intrinsecamente, as condições são as mesmas. A diferença está principalmente no fato de que uma classe social é parte de uma sociedade que habita a mesma área geográfica, enquanto $o$ contato cultural ocorre geralmente entre sociedades estabelecidas em diferentes regiões geográficas. Em ambos os casos o contato pode ter um efeito devastador sobre a parte mais fraca. A causa da degradação não é portanto a exploração econômica, como se presume muitas vezes, mas a desintegração do ambiente cultural da vítima. O processo econômico pode naturalmente fornecer o veículo da destruição, e quase invariavelmente a inferioridade econômica fará o mais fraco se render, mas a causa imediata da sua ruína não é essa razão econômica - ela está no ferimento letal infligido às instituições nas quais a sua existência social está inserida. O resultado é a perda do auto respeito e dos padrões, seja a unidade um povo ou uma classe, quer o processo resulte do assim chamado 'conflito cultural' ou de uma mudança na posição de uma classe dentro dos limites de uma sociedade ${ }^{\mathbf{1}(176)}$.

O tema acerca do futuro do trabalho segue despertando intensos e diversificados debates. Mesmo que controvertido entre especialistas, identificam-se convergências importantes em relação ao curso das mudanças no interior das sociedades urbanas e industriais.

Neste primeiro quarto do século XXI, o significado do próprio trabalho parece alterar-se, permitindo questionar, inclusive, a concepção consolidada a respeito de sua centralidade para a humanidade. Os dois principais movimentos estruturais a desestabilizar a sentido do trabalho no desenvolvimento capitalista assentam-se, mais uma vez, no excepcional progresso do avanço tecnológico em meio ao acirramento da competição intercapitalista e no papel do Estado em relação à regulação do crescente excedente de força de trabalho às necessidades do capital.

No âmbito do verdadeiro salto tecnológico percebido, as principais alterações transcorridas no interior do padrão de competição intercapitalista têm sido protagonizadas por parte da formação de grandes corporações transnacionais em meio ao avanço da globalização neoliberal, acompanhada da transição de modelos organizacionais (taylorismo, fordismo, kalmarismo, toytismo e outros) na produção e, por consequência, no trabalho. Embora se assista inegável crescimento na concentração e centralização do capital, as grandes corporações transnacionais avançaram na forma de cadeias fragmentadas de produção.

Com isso, a dispersão crescente das unidades produtivas em distintas regiões do mundo, estimuladas por transformações tecnológicas de informação e comunicação, bem como pela gigante onda de rebaixamento dos custos de trabalho, com menores restrições à segurança ambiental e ao pagamento tributário. Tudo isso patrocinado pela generalização das políticas neoliberais, cada vez mais questionadoras do sistema interestatal difundido no período após a Segunda Guerra Mundial, em oposição à dominância da era dos grandes impérios.

Para os Estados vigentes, a generalização do receituário neoliberal a questionar tanto as fronteiras nacionais como a valorizar políticas de sentido antilabor possibilitou o ataque aos sistemas de proteção social e trabalhista. O reaparecimento do desemprego massivo, acompanhado da massificação da pobreza e da extrema desigualdade na distribuição do poder, riqueza e renda, somente comparável ao início do século XX, expressou a subordinação da 
agenda do trabalho, com apequenamento das entidades representativas dos trabalhadores, como sindicatos e partidos políticos.

Em função disso, o presente artigo pretende trazer elementos de análise a respeito da agenda do trabalho neste primeiro quartel do século XXI. Inicialmente, apresentam-se aspectos relevantes acerca do movimento de desestabilização da estrutura organizacional do mundo do trabalho na antiga sociedade urbana e industrial.

Na sequência, considera-se a realidade do mundo do trabalho ante as promessas originalmente apresentadas nos debates sobre a transição para a nova sociedade de serviços. Trata-se de finalizar o artigo focando a experiência brasileira de reação à desestabilização do mundo do trabalho.

\section{Desestabilização do mundo do trabalho na sociedade urbana e industrial}

O entendimento a respeito da desestabilização do mundo do trabalho no capitalismo encontra-se associado a três determinantes fundamentais. $\mathrm{O}$ primeiro referente às históricas crises do capitalismo que revelam não apenas maiores dificuldades à classe trabalhadora, mas também oportunidades para a sua profunda reação e reestruturação.

Nesses momentos especiais, constata-se que as velhas formas de valorização do capital sinalizam esgotamentos ao passo que as novas formas ainda não se apresentam suficientemente maduras para dinamizar o sistema capitalista. Por conta disso, formas ainda mais sofisticadas de exploração da classe trabalhadora se encontram em experimentação, muitas delas subentendidas no movimento maior de financeirização do estoque da riqueza existente.

A aplicação dos novos métodos de intensificação e extensão no uso e remuneração da força de trabalho testa recorrentemente a capacidade de reação dos trabalhadores, exigindo, inclusive, o reposicionamento desafiador das instituições de organização e representação existentes no mundo do trabalho. No passado, assistiu-se ao reposicionamento dos trabalhadores perante os momentos de profundas crises e reestruturação do capitalismo mundial, como na Grande Depressão de 1873 a 1896, que terminou sendo superada por nova expansão econômica associada à Divisão Internacional do Trabalho (DIT) entre a produção de manufaturas nos países industrializados e a concentração da exportação de matérias primas e alimentos nos países agrários, como o Brasil.

Dado o conservadorismo da oligarquia rural prevalecente em grande parte dos países agrários, os esforços reformistas do final do século XIX terminaram sendo contidos às economias industrializadas diante do novo ciclo de prosperidade. Mesmo assim, a modalidade de organização dos trabalhadores qualificados nos sindicatos de ofício, embora combativos e ousados, pouco conseguiu avançar em termos de elevação das condições de vida do conjunto da classe trabalhadora.

Além disso, com o avanço do processo de mecanização, o trabalho humano se tornou apêndice da produção urbana e industrial. Perdeu, assim, o protagonismo do trabalho humano consistente com as antigas sociedades agrárias.

O resultado disso foi a instalação de enorme heterogeneidade no interior da classe trabalhadora, com mecanismos de proteção social e do trabalho proporcionados pelos sindicatos de ofício de atuação predominantemente anarcossindical (fundos de ajuda mútua e cooperativas de autoajuda) aos ocupados mais bem inseridos no desenvolvimento capitalista. Ao contrário da brava elite operária sob a tutela dos sindicatos de ofício, a parte majoritária da classe trabalhadora permaneceu exposta à livre competição, sem organização, salvo momentos especiais, cuja organização e manifestação se apresentavam fundamentalmente espontânea e desconectada da elite operária em seus aguerridos sindicatos de ofício.

Na Grande Depressão iniciada em 1929, o 
mundo do trabalho experimentou novamente uma onda de inéditas lutas até então ao sistema capitalista que se mostraram capazes de impor um novo ciclo de prosperidade, com elevação das condições de vida no conjunto dos ocupados. A formação e a extensão do fundo público, com o avanço da tributação sobre os ricos e a universalização das políticas de oferta de bens e serviços públicos, concederam ao Estado de bem-estar social a tarefa primordial de redução das desigualdades, sem alterar a natureza privada dos meios de produção.

O aparecimento e a difusão do novo sindicalismo, em oposição ao velho sindicato de ofício, permitiram a generalização dos contratos de trabalho responsável pela repartição menos desigual dos ganhos de produtividade dos ocupados. Essa nova realidade, embora centralizada nas economias de capitalismo avançado, não deixou de se manifestar também em países de industrialização tardia, como no Brasil.

Em menos de cinco décadas, alguns países em distintas regiões do planeta se tornaram urbanos, com áreas industriais avançadas. A instalação do sistema de proteção social e trabalhista e os avanços, mesmo que contidos, nas relações de trabalho possibilitaram uma plataforma de conquistas superiores ao período anterior de exploração dos trabalhadores herdado da grande crise do final do século XIX.

Dessa forma, os empregados assalariados passaram a contar com uma regulação mínima, capaz de oferecer jornada máxima de trabalho, limites às arbitrariedades patronais na contratação, demissão e aposentadoria. Em síntese, conquistas laborais jamais identificadas anteriormente no desenvolvimento capitalista, como a redução da jornada de trabalho e o pleno emprego da força de trabalho.

$\mathrm{Na}$ crise atual do capitalismo globalizado, o sistema de exploração defronta-se com novas possibilidades de protagonizar um novo salto no uso e remuneração da classe trabalhadora. Por meio da consolidação inédita do sistema de coordenação centralizada capitalista, com articulação e integração descentralizada da produção de bens e serviços pelo mundo, a força de trabalho convive com a experimentação de formas cada vez mais sofisticadas de intensificação e extensão laboral.

Em relação a isso, identifica-se a experimentação de formas de maior exploração capitalista do trabalho humano por meio do avanço da terceirização e 'Uberismo' do trabalho. Simultaneamente, percebe-se o avanço da degradação das conquistas dos trabalhadores no ambiente de flexibilização e desregulação do sistema de proteção social e trabalhista que desafiam o formato tradicional de organização e representação dos interesses dos ocupados ante a explosão sucessiva de manifestações sociais de natureza espontânea, desconectadas e desarticuladas de um projeto maior de transformação do capitalismo.

O segundo determinante fundamental da desestabilização do mundo do trabalho refere-se aos distintos padrões de desenvolvimento desigual e combinado do capitalismo que estabelecem a base material pela qual a condição da proteção social e do trabalho pode se manifestar. Isso porque o processo de acumulação do capital pressupõe a existência de um centro dinâmico capaz de combinar desigualmente o conjunto da periferia territorial que o circunda.

Em síntese, o centro dinâmico compreende três funções básicas: (i) o poder da moeda como meio de troca, reserva de valor e unidade de conta internacional; (ii) o poder militar capaz de impor pela força o que a diplomacia não alcança pelo diálogo; e (iii) a capacidade hegemônica de produzir e difundir o progresso técnico.

É nesse sentido que as revoluções industriais e tecnológicas se destacam, uma vez que restabelecem o formato da competição intercapitalista e a possibilidade de mudança no centro dinâmico do capitalismo. Exemplo disso pode ser percebido desde o final do ciclo de expansão fordista na década de 1970, com a emergência de uma nova e profunda revolução industrial e tecnológica assentada no surgimento de inédito ator global representado pelas corporações transnacionais.

Atualmente, não mais do que 500 grandes 
corporações transnacionais centralizam o controle do sistema de valor operado fragmentadamente em tão somente 300 espaços territoriais do planeta. A monopolização da produção e distribuição da riqueza em escala global torna a grande corporação transnacional mais economicamente poderosa que os Estados Nacionais. Somente nove países atualmente registram orçamento público comparável ao faturamento dos grandes monopólios privados no mundo.

Diante disso, avança a polarização entre Estados Unidos e China, apontando para uma possível transição no interior do centro dinâmico capitalista mundial. A nova fronteira de expansão capitalista aberta a partir da Ásia, cujo vetor principal tem sido o rápido e considerável processo de monopolização do capital por meio das cadeias globais de valor, coloca em xeque a hegemonia estadunidense.

O deslocamento geográfico do núcleo dinâmico mundial reflete historicamente o complexo problema de assimetria capitalista decorrente da relação entre o centro dinâmico e o conjunto de sua periferia. Enquanto a longa decadência do domínio inglês, no último quartel do século XIX, teve início com a emergência da segunda revolução industrial e com o fim do capitalismo de livre competição, a grande depressão de 1929 consolidou a hegemonia estadunidense sobre a Alemanha, derrotada nas duas grandes Guerras Mundiais (1914-1918 e 1939-1945).

Nos dias de hoje, a reorganização capitalista abre oportunidade para nova articulação entre centro dinâmico e periferia. No passado, quando não imaginava solução próxima disponível, o Brasil soube construir convergência política interna capaz de apontar nova direção para o desenvolvimento nacional ante a centralidade externa concedida pela Inglaterra até os anos de 1910 e pelos Estados Unidos no segundo pós-guerra mundial.

No período entre as décadas de 1880 e 1930, por exemplo, o esforço nacional foi determinante para que os novos rumos aparecessem ao Brasil. A realização das reformas política (1881), laboral (1888), na forma de governo (1889) e constitucional (1891) no final do século XIX favoreceu a passagem para sociedade de classes movida pelo capitalismo no país herdeiro da antiga sociedade escravista dependente da primitiva economia mercantil primário-exportadora, incapaz de generalizar qualquer forma de proteção social e do trabalho.

Também foi registrada inovadora configuração política a partir da Revolução de 1930, responsável pelo desencadeamento de inédito ciclo econômico de expansão conferido pelo projeto de industrialização nacional. Com isso, as condições materiais necessárias à instalação do sistema de proteção social e do trabalho foram sendo estabelecidas durante a transição da antiga e primitiva sociedade agrária para a moderna sociedade urbana e industrial, o que permitiu fundar as bases do Estado desenvolvimentista no Brasil.

Atualmente, o impasse imposto pelo Golpe de Estado não deixa de expressar certa reação de parte dos Estados Unidos, enquanto decadente centro dinâmico perante o avanço das relações do Brasil com os Brics, por exemplo. A experiência brasileira de constituição da política externa altiva e ativa, com a emergência da internacionalização da grande empresa nacional nos anos 2000, indicou um novo caminho de expansão em pareceria com o centro dinâmico mundial em formação e que se assenta na Ásia.

Por fim, o terceiro determinante da desestabilização do mundo do trabalho relaciona-se com a capacidade de o Estado organizar, produzir e sustentar no tempo diversas políticas públicas, especialmente a de proteção social e do trabalho. Sabe-se que a principal experiência de constituição do sistema de proteção social e do trabalho transcorreu positivamente durante a interrupção da primeira onda de globalização capitalista verificada entre os anos de 1930 e de 1980.

Acontece que, nas décadas de 1870 e 1920, com o auge da primeira onda de globalização capitalista liderada pelo Reino Unido, o Brasil reafirmou a sua posição subordinada e dependente à antiga DIT. Na época, a dominância 
das forças de mercado sobre a política tornava os partidos existentes (Liberal e Conservador) no regime da Monarquia (1822 - 1889), equivalentes na defesa da não interferência do Estado mínimo na economia e sociedade.

Mesmo com a República Velha (1889 1930), os princípios liberais foram mantidos, mostrando-se insuficientes para estancar as elevadas desigualdades e preconceitos forjados por quase quatro séculos de hegemonia escravista. Ao ser identificado pela elite como inábil e indolente, a base da pirâmide social foi excluída da estrutura produtiva, ocupada crescentemente pela mão de obra branca imigrante, base original da organização do velho sindicalismo de ofício.

Qualquer iniciativa de regulação do mercado de trabalho, por exemplo, era considerada inconstitucional, inaceitável para ser exercida pelo Estado mínimo. A questão social, por conta disso, seguiu sendo tratada como caso de polícia.

Somente com o interregno da primeira onda de globalização capitalista no início do século XX que mudanças mais significativas passaram a ocorrer em relação à proteção social e do trabalho no Brasil. Nesse sentido, as experiências de socialismo real representado pela Revolução Russa (1917), de gravidade na Grande Depressão de 1929 e da trágica realização das duas grandes guerras mundiais, prosseguida pelo rearmamento inserido na Guerra Fria (1947 - 1991), favoreceram, em grande medida, a fase do desenvolvimento de ouro no capitalismo regulado a partir da centralidade dos Estados Unidos ao longo da segunda metade do século XX.

Nesse sentido, percebe-se que, no Brasil, durante as décadas de 1930 a 1970, a transição da arcaica e longeva sociedade agrária para a moderna sociedade urbana e industrial transcorreu acompanhada por reformas efetuadas nas esferas da organização do Estado desenvolvimentista. Destacam-se, por exemplo, a democratização do regime político, a generalização do direito do trabalho, a expansão da instrução pública, entre outras.

Todas elas se mostraram funcionais $\mathrm{e}$ eficazes ao deslocamento da posição brasileira na DIT de mero exportador de commodities na década de 1920 para a $8^{\text {a }}$ economia industrial mais importante do mundo em 1980. Mesmo assim, o sistema de proteção social e do trabalho não foi universalizado, mantendo o seu funcionamento na forma de monopólios sociais desigualisadores de oportunidades e da ascensão social para parcela da classe trabalhadora.

Somente pela Constituição Federal de 1988 e com a experiência das políticas públicas universais na década de 2000 que o sistema de proteção social e do trabalho avançou consideravelmente no Brasil. Entretanto, foi pela atual reestruturação capitalista imposta pela segunda onda de globalização conduzida por grandes corporações transnacionais e sob a dominância financeira que a capacidade do Estado de sustentar políticas públicas passou a contida, trazendo repercussões negativas não somente à proteção social e do trabalho.

\section{Promessas e realidades}

Embalados certamente por certo determinismo tecnológico e por saltos imaginados na produtividade do trabalho imaterial, uma nova gama de promessas foi sendo forjada pelos ideólogos do desenvolvimento capitalista em direção à almejada sociedade do tempo livre estendida pelo avanço do ócio criativo, da educação em período integral e da contenção do trabalho heterônomo (apenas pela sobrevivência). Penetrados cada vez mais pela cultura midiática do individualismo e pela ideologia da competição, o neoliberalismo seguiu ampliando apoiadores no mundo.

Com isso, surgiu a perspectiva de que as mudanças nas relações sociais repercutiriam inexoravelmente sobre o funcionamento do mercado de trabalho. Com a transição demográfica, novas expectativas foram sendo apresentadas. A propaganda de elevação da expectativa de vida para próximo de 100 anos de idade, como exemplo, deveria abrir inédita perspectiva à postergação do ingresso no 
mercado de trabalho para a juventude completar o ensino superior, estudar a vida toda e trabalhar com jornadas semanais de até 12 horas.

A nova sociedade pós-industrial, assim, estaria a oferecer um padrão civilizatório jamais alcançado pelo modo capitalista de produção e distribuição. Assim, foi sob este manto de promessas de maior libertação do homem do trabalho pela luta da sobrevivência (trabalho heterônomo) por meio da postergação da idade no ingresso ao mercado de trabalho para somente depois do cumprimento do ensino superior, bem como da oferta educacional ao longo da vida, que o racionalismo neoliberal se constituiu.

De certa forma, trouxe o entendimento de que o esvaziamento do peso relativo da economia nacional proveniente dos setores primário (agropecuária) e secundário (indústria e construção civil) consagraria expansão superior do setor terciário (serviços e comércio). Enfim, estaria por surgir a sociedade pós-industrial protagonista de conquistas superiores aos marcos do possibilitado desde a década de 1930, possível sem luta, pois contrária às classes sociais em uma sociedade fundada no indivíduo portador de competitividade e promotor do seu próprio seguro de vida e previdência, não mais dependente do Estado.

Essas promessas, contudo, não se tornaram efetivas, tampouco resultaram da imaginada modernização neoliberal. Em pleno curso da transição para a sociedade de serviços, a inserção no mercado de trabalho precisa ser gradualmente postergada, possivelmente para o ingresso na atividade laboral somente após a conclusão do ensino superior, com idade acima dos 22 anos, e saída sincronizada do mercado de trabalho para o avanço da inatividade; tudo isso acompanhado por jornada de trabalho reduzida, o que permitiria que o trabalho heterônomo passasse a corresponder a não mais do que $25 \%$ do tempo da vida humana.

É nesse sentido que se pode identificar uma linha perspectiva do trabalho humano associado às lutas de classe e à maior capacidade de atuação pública por meio do Estado democrático. Destaca-se que, na antiga sociedade agrária, o começo do trabalho ocorria a partir dos 5 a 6 anos de idade para se prolongar até praticamente a morte, com jornadas de trabalho extremamente longas (14 a 16 horas por dia) e sem períodos de descanso, como férias e inatividade remunerada (aposentadorias e pensões). Para alguém que conseguisse chegar aos 40 anos de idade, tendo iniciado o trabalho aos 6 anos, por exemplo, o tempo comprometido somente com as atividades laborais absorvia cerca de $70 \%$ de toda a sua vida.

$\mathrm{Na}$ sociedade industrial, o ingresso no mercado laboral foi postergado para os 16 anos de idade, garantindo aos ocupados, a partir daí, o acesso a descanso semanal, férias, pensões e aposentadorias provenientes da regulação pública do trabalho. Com isso, alguém que ingressasse no mercado de trabalho depois dos 15 anos de idade e permanecesse ativo por mais 50 anos teria, possivelmente, mais alguns anos de inatividade remunerada (aposentadoria e pensão).

Assim, cerca de $50 \%$ do tempo de toda a vida estaria comprometido com o exercício do trabalho heterônomo. A parte restante do ciclo da vida, não comprometida pelo trabalho e pela sobrevivência, deveria estar associada à reconstrução da sociabilidade, estudo e formação, cada vez mais exigidos pela nova organização da produção e distribuição internacionalizada.

Isso porque, diante dos elevados e constantes ganhos de produtividade, tornou-se possível reduzir o tempo semanal de trabalho de algo ao redor das 40 horas para não mais que 20 horas. De certa forma, a transição entre as sociedades urbano-industrial e pós-industrial tenderia a não mais separar nítida e rigidamente $o$ tempo do trabalho do não trabalho, podendo gerar maior mescla entre os dois, com mais intensidade e risco de longevidade ampliada da jornada laboral para além do tradicional local de exercício efetivo do trabalho.

É dentro desse contexto que se recolocaria em novas bases a relação do tempo de trabalho heterônomo e a vida. Em geral, o funcionamento do mercado de trabalho relacionado, ao 
longo do tempo, com uma variedade de formas típicas e atípicas de uso e remuneração da mão de obra com excedente de força de trabalho derivado dos movimentos migratórios internos e externos sem controles, conforme apontado originalmente por autores que imaginaram superior a passagem da antiga sociedade urbana e industrial para a de serviços (terciária).

No entanto, após quase quatro décadas de geração das promessas neoliberais voltadas à construção de uma sociedade superior, registra-se, pelo contrário, o fortalecimento de sinais inegáveis de regressão no interior da sociedade do capital em avanço também no Brasil. Do progresso registrado em torno da construção de uma estrutura social medianizada por políticas sociais e trabalhistas desde a década de 1930, constata-se, neste início do século XXI, o retorno da forte polarização social.

Por uma parte, a degradação da estrutura social herdada da industrialização fordista tem desconstituído ampla parcela da classe média, fortalecendo a expansão do novo precariado no conjunto da classe trabalhadora. Por outra, a concentração de ganhos significativos de riqueza e renda em segmento minoritário da população gera contexto social inimaginável, em que somente parcela contida da sociedade detém parcelas crescentes da riqueza.

Em mais de três décadas de predomínio da regulação neoliberal do capitalismo, as promessas da construção de padrão civilizatório superior encontram-se desfeitas. Os avanços ocorridos têm sido para poucos, enquanto o retrocesso observado serve a muitos.

\section{Desestabilização e resistência no Brasil}

A confirmação do regresso à fase da desregulação e flexibilização das políticas sociais e trabalhistas impõe novo padrão de exploração à classe trabalhadora. Com a decadência do padrão de industrialização e regulação fordista, o Brasil dá sequência ao movimento maior de desestruturação da sociedade salarial, especialmente aquela conformada pela maior proximidade entre a base e o cume da estrutura social.

Assiste-se, assim, à transição das tradicionais classes médias assalariadas e de trabalhadores industriais para o inédito e extensivo precariado, com importante polarização social permeada pelo espontaneismo de características cada vez mais anárquicas. Concomitantemente com as novas tecnologias de comunicação, as mobilizações sociais e trabalhistas transcorrem acima da setorialização e fragmentação da tradicional organização sindical, o que gera estranhamento e distanciamento entre as estruturas existentes e as formas de mobilização social e política espontâneas.

$O$ vazio proporcionado pela desindustrialização vem sendo ocupado pela chamada sociedade de serviço, que constitui, nesse sentido, uma nova perspectiva de mudança estrutural no mundo do trabalho. Mudança esta que torna cada vez maior o padrão de exploração do trabalho diante do esvaziamento da regulação social e trabalhista e das promessas de modernidade pelo receituário neoliberal que não se realizam.

A longa jornada de efetivação da regulação do mundo do trabalho no Brasil parece estar com seus dias contados perante o sinal verde concedido pela interdição do governo democraticamente eleito em 2014. Com o impedimento da presidenta Dilma em 2016, uma série de projetos liberalizantes da legislação social e trabalhista que se encontrava represada desde a ascensão em 2003 dos governos liderados pelo Partido dos Trabalhadores passou a ser a descortinada.

Com isso, o Brasil passou a conviver com uma quarta onda de flexibilização do sistema de proteção social e trabalhista instituído a partir da década de 1930, quando passou a se consolidar a transição da velha sociedade agrária para a urbana e industrial. Isso porque a constituição do mercado nacional de trabalho resultou de uma lenta transição de 80 anos, iniciada em 1850, com o fim do tráfico de escravos e com a implantação da lei de terras, a finalizada em 
1930, com a superação da condição de mercados regionais de trabalho.

Mesmo diante da passagem do Império para a República em 1889, a regulação do mercado de trabalho terminou sendo postergada ante a prevalência da situação de 'liberdade do trabalho' definida pela primeira constituição republicana, em 1891. Nem mesmo a aprovação, em 1926, da emenda constitucional 29, que possibilitou ao Congresso Nacional legislar sobre o tema do trabalho, alterou a perspectiva liberal de manutenção do Estado fora da regulação social e trabalhista.

A partir da Revolução de 1930, contudo, a regulação do trabalho passou a ser uma novidade, difundida fragmentadamente, segundo pressão localizada nas categorias mais fortes e mais bem inserida no desenvolvimento capitalista. Após uma década de embates, com avanços pontuais na implementação de leis dispersas de regulação do emergente emprego assalariado, foi implementada a Consolidação das Leis do Trabalho (CLT) no ano de 1943, em pleno regime político autoritário do Estado Novo (1937 - 1945).

Mesmo assim, a maior parte dos trabalhadores esteve excluída do código do trabalho diante da oposição liberal conservadora dos proprietários rurais, antiga força dominante na República Velha (1889 - 1930). Até o ano de 1963, com a aprovação do Estatuto do Trabalhador Rural, que abriu a possibilidade de incorporação lenta e gradual do trabalho rural, a CLT voltava-se tão somente às relações de trabalho urbanas.

Foi pela Constituição Federal de 1988, ou seja, 45 anos após a implementação da CLT, que os trabalhadores rurais passaram a ter direitos equivalentes aos empregados urbanos, embora ainda hoje tenham segmentos dos ocupados sem acesso à regulação social e trabalhista. Na década de 1940, por exemplo, a CLT mal atingia $10 \%$ dos ocupados, enquanto nos dias de hoje chegou a superar os dois terços dos trabalhadores.

Com a recessão e os retrocessos do atual governo golpistas, a involução da proteção social e trabalhista avança. A aprovação das reformas neoliberais desencadeadas mais recentemente elevará ainda mais o grau de exclusão no Brasil.

Diante disso, destaca-se uma primeira onda de flexibilização da legislação social e trabalhista transcorrida a partir da segunda metade da década de 1960, com a ascensão da Ditadura Militar (1964 - 1985). Na oportunidade, a implantação do Fundo de Garantia por Tempo de Serviço (FGTS), por exemplo, não apenas interrompeu a trajetória de estabilidade no emprego, como também inaugurou enorme rotatividade na contração e demissão da mão de obra no Brasil.

A taxa de rotatividade que atingia cerca de $15 \%$ da força de trabalho ao ano na década de 1960 rapidamente foi acelerada, aproximando-se da metade dos empregos formais do País. Com isso, a generalização do procedimento patronal de substituir empregados de maior salário por trabalhadores de menor remuneração.

$\mathrm{Na}$ política salarial vigente entre 1964 e 1994, o resultado foi, em geral, a perda de poder de compra do rendimento dos trabalhadores, sobretudo no valor real do salário mínimo, que atende à base da pirâmide distributiva do País. Diante da significativa expansão da produtividade do trabalho, os salários perderam a corrida para a inflação, o que contribuiu ainda mais para o agravamento da desigualdade de renda no Brasil.

Essa segunda onda de flexibilização se caracterizou por deslocar a evolução dos rendimentos do trabalho do comportamento acelerado da produtividade, trazendo, por consequência, a prevalência de uma economia industrial de baixos salários. Ao mesmo tempo, uma enorme desigualdade tanto intrarrendimento do trabalho entre altas e baixas remunerações como entre o rendimento do trabalho e as demais formas de renda da propriedade (juros, lucros, aluguéis e outras).

A terceira onda de flexibilização das relações de trabalho pode ser constatada na década de 1990, com a dominação de governos com 
orientação neoliberal. Dessa forma, assistiu-se à generalização de medidas de liberalização da contratação de trabalhadores por modalidades abaixo da orientação estabelecida pela CLT. Entre elas, a emergência da terceirização dos contratos, em plena massificação do desemprego e precarização das relações de trabalho.

A partir da metade da década de 2010, todavia, desencadeou-se uma quarta onda de flexibilização das leis sociais e trabalhistas. Com a recente e parcial derrota dos trabalhadores imposta pela Câmara dos Deputados pela aprovação da legislação para terceirização, a septuagenária CLT encontra-se novamente ameaçada de ser rebaixada.

A atualidade do projeto de lei da terceirização a ser ainda avaliado pelo Senado Federal e que conta com o apoio antecipado do governo Temer encontra-se em sua ramificação com a perspectiva de generalização da 'Uberismo' laboral neste início do século XXI, bem como com a destruição do sistema de negociação coletiva de trabalho e de proteção social e trabalhista. Isso porque o modo Uber de organizar e remunerar a força de trabalho distancia-se crescentemente da regularidade do assalariamento formal, acompanhado geralmente pela garantia dos direitos sociais e trabalhistas.

Os experimentos de 'Uberismo' do trabalho avançam em forma diversificada no espaço supranacional. Começaram com iniciativas no transporte individual, por meio da desregulamentação generalizada na oferta de sistema de taxis por aplicativos decorrentes das tecnologias de informação e comunicação, até alcançarem atualmente os contratos de zero hora, cujo trabalhador permanece em casa aguardando a demanda de sua força de trabalho advinda de qualquer parte do mundo.

Tudo isso à margem da regulação nacional de trabalho, fruto da generalização das novas tecnologias de informação e comunicação em meio ao enorme excedente de mão de obra. O esfacelamento das organizações de representação de interesses dos trabalhadores (associações, sindicatos e partidos) transcorre como consequência geral dessa nova fase de intensificação da exploração do trabalho.

Como os direitos sociais e trabalhistas passam crescentemente a ser tratados pelos empregadores e suas máquinas de agitação e propaganda enquanto fundamentalmente custos, a contratação direta, sem direitos sociais e trabalhistas libera a competição individual maior entre os próprios trabalhadores em favor dos patrões. Os sindicatos ficam de fora da negociação, contribuindo ainda mais para esvaziamento do grau de organização em sua própria base social e territorial.

Ao depender cada vez mais do rendimento diretamente recebido, sem a presença do histórico salário indireto (férias, feriado, previdência etc.), os fundos públicos voltados ao financiamento do sistema de seguridade social enfraquecem, quando não contribuem para a prevalência da sistemática do rentismo. A contenção da terceirização, em função disso, poderia estancar a trajetória difusora do modo Uber de precarização das contratações de trabalho.

\section{Considerações finais}

Para um país em tardia busca pelo seu desenvolvimento sustentável, estabelece-se uma das poucas vantagens associadas à possibilidade de inversão profunda das prioridades governamentais até então assumidas. Diante da atual reestruturação capitalista imposta pela segunda onda de globalização conduzida pelas grandes corporações transnacionais e sob a dominância financeira, o mundo do trabalho tem ocupado centralidade na agenda tanto na estratégia de competição internacional como na definição das opções do desenvolvimento das nações. Exemplo disso tem sido a lógica do mundo dos negócios invadindo as decisões de reformas sociais e trabalhistas, capaz de desconstruir direitos e restringir a atuação sindical.

A retomada do desenvolvimento brasileiro, nesse sentido, requer a revisão da perspectiva neoliberal assentada na produção e difusão da 
via individual, não classista do mundo. Por uma parte, porque a degradação da estrutura social herdada da industrialização fordista tem desconstituído ampla parcela da classe média, bem como fortalecido a expansão do novo precariado no conjunto da classe trabalhadora.

Por outra, porque a concentração de ganhos significativos de riqueza e renda em segmento minoritária da população gera contexto social inimaginável, em que somente parcela contida da população passa a deter mais riqueza que a maior parte do conjunto dos habitantes do Brasil. Em mais de três décadas de predomínio da regulação neoliberal do capitalismo, as promessas da construção de padrão civilizatório superior encontram-se desfeitas, uma vez que os avanços ocorridos têm sido para poucos; e o retrocesso generalizado, para muitos.

$\mathrm{Na}$ crise atual do capitalismo globalizado, o sistema de exploração se defronta com novas possibilidades de protagonizar um novo salto no uso e remuneração da classe trabalhadora. A consolidação inédita do sistema de coordenação centralizada capitalista, com articulação e integração descentralizada da produção de bens e serviços pelo mundo, expõe a força de trabalho a formas cada vez mais sofisticadas de exploração.

O protagonismo periférico descortina oportunidade inédita de mudança substancial na ordem mundial, com perspectivas de redução do brutal grau de desigualdade existente entre países e classes sociais. Todavia isso ainda pressupõe convergência e coordenação global ainda inexistente nos dias de hoje.

Ademais, o governo brasileiro atual sequer se apresenta preparado para dar conta das perspectivas abertas neste início do século XXI. Pelo contrário, a ruptura democrática ocorrida a partir de 2016 impôs o predomínio de pauta desconstrutiva dos direitos sociais e trabalhistas.

Por conta disso, a turbulência política deve seguir o seu turno, acelerando, possivelmente, a maturação de outra convergência para a economia e sociedade brasileira. As reações por parte dos trabalhadores têm sido importantes, ainda que nem sempre suficientes para barrar o avanço do receituário neoliberal.

\section{Referência}

1. Polanyi K. A grande transformação. 2. ed. Rio de Janeiro: Campus; 2000. 